\title{
Recovery of root growth and physiological characters in cotton after salt stress relief
}

\author{
Wen-Qi Guo ${ }^{1}$, Pei-Tong Zhang ${ }^{1 *}$, Chun-Hong Li ${ }^{1}$, Jian-Mei Yin ${ }^{1}$, and Xiao-Yong Han ${ }^{1}$
}

\begin{abstract}
Crop growth in a saline environment depends on its tolerance to salt stress and capacity to recover after salt stress relief. To evaluate recovery mechanisms in cotton after salt stress relief, the changes of plants growth, root vigor, lipid peroxidation, antioxidant enzymes activity, organic solutes in root after salt stress relief were studied for two cotton (Gossypium hirsutum L.) cultivars (Lumianyan 37 and Sumian 22) grown under control (salt content of soil grown cotton was maintained at $0.2 \%$ ), salt stressed (salt content of soil grown cotton was maintained at $0.5 \%$ ) and salt recovered (salt content of soil grown cotton was reduced from $0.5 \%$ to $0.2 \%$ level at the $57 \mathrm{~d}$ after seeding) conditions. The results showed that root and shoot growth rate and root vigor significantly increased after salt stress relief, and the increase in growth rate and root vigor was more pronounced in 'Lumianyan 37'. In salt-recovered root, malondialdehyde (MDA) content decrease, the activities of superoxide dismutase (SOD) and peroxidase (POD) decreased, but catalase (CAT) activity increased compared with those in the salt-stressed root. For salt-recovered root, MDA content and POD activity of 'Lumianyan 37' was lower, while the SOD and CAT activities were higher. Salt-recovered cotton root showed a decrease in soluble sugar and free amino acid content compared with the salt-stressed root, especially in 'Lumianyan 37'. The results indicated that growth and root metabolism of cotton plants gradually recovered after salt stress relief, and the high capacity of cotton plants to recover after salt stress relief may be related to the high capacity of antioxidative system and the high utilization capacity of organic solutes as important nutritional components in root.
\end{abstract}

Key words: Antioxidant enzyme, Gossypium hirsutum, organic solute, recovery, salt stress relief, root vigor.

\section{INTRODUCTION}

Soil salinity has been considered one of the major limiting factors for crop productivity and agricultural sustainability worldwide, especially in arid and semi-arid regions, limited rainfall, high evapotranspiration, and inadequate fresh water management have contributed to an increase in soil salinity (Meloni et al., 2003; Munns, 2005; Dong et al., 2010). Cotton (Gossypium hirsutum L.) is grown widely in these regions because of its high drought and salinity tolerance (Chen et al., 2010). However, salinity tolerance of cotton is still restricted, excessive salt in the soil inhibits cotton growth and development, finally leading to reduced lint yield and fiber quality (Ahmad et al., 2002; Sairam and Tyagi, 2004; Munns and Tester, 2008).

Soil salt accumulation can change with time and place, as soil management, irrigation method, and weather conditions (Dong et al., 2010). These changes can enhance or reduce the salt effects on physiological responses, and further affect plant growth and development (de Lacerda et al., 2005; Dong et al., 2008). So crop productivity in saline environment depends on not only its tolerance to salt stress but also capacity to recover from salt

${ }^{1}$ Institute of Industrial Crops, Jiangsu Academy of Agricultural Sciences, Nanjing, Jiangsu 210014, China.

"Corresponding author (wenqi_guo@126.com).

Received: 23 July 2014.

Accepted: 27 October 2014.

doi:10.4067/S0718-58392015000100012 stress. However, at present, more attention is paid to physiological mechanisms of salt stress or salt tolerance in cotton (Chen et al., 2010; Zhang et al., 2013), there is little study evaluating cotton recovery after salt stress relief.

The decline in plant growth due to salinity is associated with oxidative damage caused by an increased production of reactive oxygen species (ROS), such as superoxide anion radicals $\left(\mathrm{O}_{2}^{-}\right)$and hydrogen peroxide $\left(\mathrm{H}_{2} \mathrm{O}_{2}\right)$ (Meloni et al., 2003; Parida et al., 2004; Oueslati et al., 2010). These ROS disrupt normal metabolism through peroxidating membrane lipids, which causes degradation and impairment of structural components and leads to membrane leakage (Munns and Tester, 2008). In order to avoid oxidative damage caused by ROS, plants have evolved defense systems that both limit the formation of ROS and promote its removal (Ashraf, 2002; De Azevedo Neto et al., 2006; Moradi and Ismail, 2007). As the most important components in the scavenging system of ROS, antioxidative enzymes like superoxide dismutase (SOD), peroxidase (POD), catalase (CAT) can minimize the cellular damage caused by ROS (Ahmad et al., 2002; Tuna et al., 2008; Liu and Zhang, 2011; Mallik et al., 2011). Previous researches on cotton have established a correlation between antioxidant ability and salinity tolerance (Meloni et al., 2003). However, after salt stress relief, the change of antioxidant enzymes activity contributing to the alleviation in oxidative damage may also play a key role in recovering process from salt stress 
(Cavalcanti et al., 2007), but these physiological processes in cotton are still unclear and need further study.

The accumulation of low molecular-weight solutes, like amino acid and sugars, is one of the most important responses of plant to salt stress (Lehner et al., 2008; Chen et al., 2011). These organic solutes may contribute to osmotic adjustment, and enable plants to maintain higher turgor, protecting cell structure and function (Wang and Han, 2009). Moreover, the accumulation of organic solutes may be important to serve as metabolic or energetic reserve for plant recovery from salt stress (de Lacerda et al., 2005). Therefore, studies on changing of organic solutes in cotton after salt stress relief could provide valuable information for explaining the physiological mechanism of recovery from salt stress.

Root is the first affected parts of a plant directly faced to salt stress and the major organ for uptake of water and nutrients. Root development and activity are inhibited when plant grown in saline environment, which causes a series of depressive effects in the physiological functions of aerial parts (Cavalcanti et al., 2007; Zhang et al., 2013). So recovery of root growth and activity is the key to plant after the alleviation of salt stress. The present study was conducted to investigate on growth, root vigor, malondialdehyde (MDA), antioxidant enzyme activities, soluble sugar, and free amino acid content in root of two cotton cultivars to evaluate the physiological mechanism of recovery in cotton after salt stress relief.

\section{MATERIALS AND METHODS}

\section{Plant materials, growth conditions, and treatments}

Pot experiments were conducted in the summer seasons of 2011 and 2012 in a glasshouse, at Jiangsu Academy of Agricultural Sciences, located at Nanjing $\left(32^{\circ} 02^{\prime} \mathrm{N}\right.$, $118^{\circ} 50^{\prime}$ E), Jiangsu Province of China. Seeds of two cotton (Gossypium hirsutum L.) cultivars (Lumianyan 37 and Sumian 22) were sown in plastic pots on 8 May 2011 and 6 May 2012. Fifteen cotton seeds were sown per pot. When seedlings had three true leaves, plants were thinned to retain a healthy and uniform plant per pot. Plastic pots were $40 \mathrm{~cm}$ high and $40 \mathrm{~cm}$ wide, filled with $20 \mathrm{~kg}$ soil. The chemical properties of the soil are shown in Table 1. Soil water content of pots was monitored daily by weighing. The pots were watered to maintain the soil relative water content in the range of $70-85 \%$.

Three salinity treatments were performed for each cotton cultivar. The mixed salt including five kinds of salts (sodium chloride $77.7 \%$, magnesium chloride $7.3 \%$, magnesium sulfate $9.6 \%$, calcium chloride $3.3 \%$, and potassium chloride $2.1 \%$ ) was applied in this study, which was mixed into natural-dried soil according to the given salt/dry soil ratio. Three salt treatments were established: (1) Control (CK), in which the salt content of soil was maintained at $0.2 \%(\mathrm{w} / \mathrm{w}$, dry soil weight base) during whole growth period; (2) salt-stressed treatment (S), in
Table 1. Chemical properties of the soil used for the experiments in 2011 and 2012.

\begin{tabular}{lcc}
\hline Treatments & 2011 & 2012 \\
\hline Organic matter, $\mathrm{g} \mathrm{kg}^{-1}$ & $13.1 \pm 0.5$ & $14.4 \pm 0.7$ \\
Total N, g kg & $0.52 \pm 0.1$ & $0.61 \pm 0.2$ \\
Alkali hydrolyzable N, mg kg-1 & $43.5 \pm 0.1$ & $54.6 \pm 1.2$ \\
Available P, mg kg & $31.0 \pm 0.4$ & $33.2 \pm 0.9$ \\
Available K, mg kg-1 & $168 \pm 3.0$ & $174 \pm 4.0$ \\
Soil total salt, $\mathrm{g} \mathrm{kg}^{-1}$ & $0.45 \pm 0.1$ & $0.38 \pm 0.0$ \\
\hline
\end{tabular}

Data are mean \pm SE of three replicates.

which the salt content of soil was gradually increased from $0.2 \%$ to $0.5 \%$ (only increased $0.1 \%$ a week) when the seedlings had two true leaves (15 d after seeding), and was maintained till harvest time; (3) salt-recovered treatment (SR), in which the salt content of soil was gradually increased from $0.2 \%$ to $0.5 \%$ (only increased $0.1 \%$ a week) when the seedlings had two true leaves (12 $\mathrm{d}$ after seeding), and was maintained during a period of 30 $\mathrm{d}$, soil salinity was then rinsed to $0.2 \%$ with clear water at the $57 \mathrm{~d}$ after seeding. The salt content of soil is shown in Figure 1. The experiment was arranged in a completely random design. Each treatment had 20 replicates, and one pot with a single plant represented one replicate.

\section{Determination of plant growth}

At $1,7,14$, and $21 \mathrm{~d}$ after salt stress relief, three cotton plants from each treatment were cut at the cotyledon node. The root was separated from the soil by rinsing soil with clear water. Samples of $0.5 \mathrm{~g}$ of white young root were
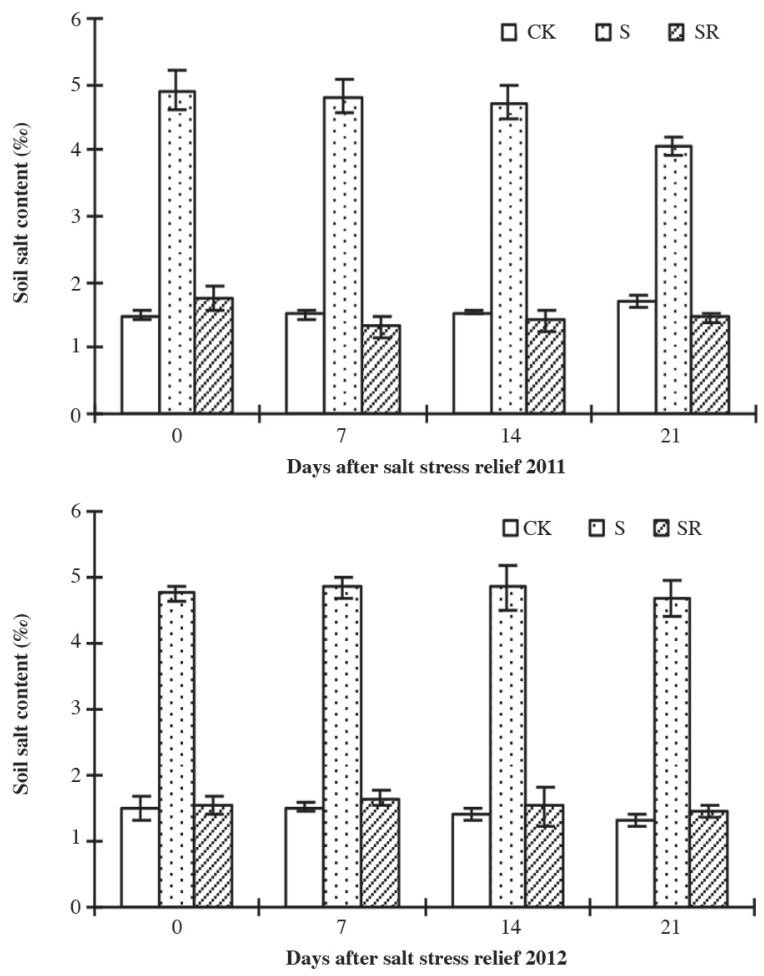

Figure 1. Changes of soil salt content of control (CK), salt-stressed (S), and salt-recovered (SR) treatment during salt stress recovery in 2011 and 2012. 
used to assess root vigor immediately, and samples of 5.0 $\mathrm{g}$ of white young root were immediately frozen in liquid $\mathrm{N}_{2}$ and stored at $-70{ }^{\circ} \mathrm{C}$ for enzyme-activity and organic solutes analysis. Then root, leaves, stems, branches, flowers, and bolls were oven-dried at $80{ }^{\circ} \mathrm{C}$ to constant weight, and DM was determined.

\section{Root vigor assessments}

The dehydrogenase activity in root is regarded as an indicator of root vigor. TTC is a chemical that is reduced by dehydrogenases in root, and then generate red and water-fast triphenyltetrazolium formazan (TTF). Accordingly, measurement of root vigor in this study was executed according to the triphenyltetrazolium chloride (TTC) (Sinopharm Chemical Reagent, Shanghai, China) method ( $\mathrm{Li}, 2000)$. Root of $0.5 \mathrm{~g}$ were placed in tubes, filled with $5 \mathrm{~mL} 0.4 \%$ TTC and $5 \mathrm{~mL} 0.06 \mathrm{M}$ phosphate buffer, pH 7.0. The tubes were incubated at $37^{\circ} \mathrm{C}$ for up to $3 \mathrm{~h}$. The chemical reaction was stopped by adding $2 \mathrm{~mL}$ of $1 \mathrm{M}$ sulfuric acid in the tubes. The extraction with TTF was conducted in tubes filled with 3-4 mL ethyl acetate and ground with a pestle. The liquid phase was removed into a test tube. Ethyl acetate (Sinopharm Chemical Reagent, Shanghai, China) was added to the $10 \mathrm{~mL}$ level and optical density (OD) values were recorded with a UVVis recording spectrophotometer (UV-2401, Shimadzu Corporation, Japan) at $485 \mathrm{~nm}$. The OD values were used to calculate the equivalent TTF concentrations by which the root vigor was determined for each root fresh weight as TTF reduction $(\mu \mathrm{g})$ per gram of root fresh weight per hour (TTF $\mu \mathrm{g} \mathrm{g}^{-1} \mathrm{FW} \mathrm{h}^{-1}$ ).

\section{Determination of MDA content and antioxidant enzyme activity}

Frozen root segments $(0.5 \mathrm{~g})$ were crushed into fine powder in a mortar in an ice-bath. To each sample, $5 \mathrm{~mL}$ of $0.05 \mathrm{M}$ phosphate buffer $(\mathrm{pH} \mathrm{7.8)}$ with $1 \%$ polyvinylpyrrolidone (Sinopharm Chemical Reagent, Shanghai, China) was used as an extraction buffer. The homogenate was centrifuged at $15000 \mathrm{~g}$ for $15 \mathrm{~min}$ at $4{ }^{\circ} \mathrm{C}$. The supernatant was used to measure antioxidant enzyme activities and malondialdehyde (MDA) content according to the method of $\mathrm{Li}$ (2000). One unit of SOD activity was defined as the amount of enzyme required to cause $50 \%$ inhibition of nitro blue tetrazolium (NBT) (Sigma, Saint Louis, Missouri, USA) reduction, measured with a UV-Vis recording spectrophotometer (UV-2401, Shimadzu Corporation, Japan) at $560 \mathrm{~nm}$. Catalase activity was determined by potassium permanganate titration. The action mixture contained $2.9 \mathrm{~mL}$ of $50 \mathrm{mM}$ phosphate buffer (pH 7.0), $1.0 \mathrm{~mL} 10 \mathrm{mM} \mathrm{H}_{2} \mathrm{O}_{2}$ and $100 \mu \mathrm{L}$ enzyme extract in tubes. Peroxidase (POD) activity was analyzed in $2.9 \mathrm{~mL}$ of $0.05 \mathrm{M}$ phosphate buffer containing $1.0 \mathrm{~mL}$ of $0.05 \mathrm{M}$ guaiacol (Sinopharm Chemical Reagent, Shanghai, China) and $1.0 \mathrm{~mL} 2 \% \mathrm{H}_{2} \mathrm{O}_{2}$. The increase in absorbance at $470 \mathrm{~nm}$ was measured with a UV-Vis recording spectrophotometer (UV-2401, Shimadzu Corporation, Japan) after adding $2.0 \mathrm{~mL} \mathrm{20 \%} \mathrm{chloroacetic} \mathrm{acid.} \mathrm{MDA}$ content was calculated from the absorbance at $532 \mathrm{~nm}$ (correction was done by subtracting the absorbance at 600 $\mathrm{nm}$ for unspecific turbidity) by using extinction coefficient of $155 \mathrm{mM}^{-1} \mathrm{~cm}^{-1}$. All the above procedures of enzyme extraction were carried out at $0-4{ }^{\circ} \mathrm{C}$.

\section{Determination of soluble sugar and free amino acid}

A sample $(0.3 \mathrm{~g})$ of fresh mass of root was extracted with $10 \mathrm{~mL}$ of demineralized water in a boiling water-bath for $30 \mathrm{~min}$, and then was filtered into a volumetric flask. This extraction was repeated thrice and the volume completed to $25 \mathrm{~mL}$ with demineralized water. In this extract, soluble sugar was analyzed colorimetrically according to the anthrone method, free amino acid according to the ninhydrin method (Li, 2000).

\section{Statistical analysis}

Data were statistically analyzed using SPSS 11.0 software (IBM Corporation, Armonk, New York, USA) or Microsoft Excel (Microsoft, Bothell, Washington, USA). Each data point was the mean of three replicates. Treatment means were separated using Fisher's protected least significant difference (LSD) test at 95\% level of probability. Figures were illustrated using Microsoft Excel 2003. In all the figures, the spread of values is shown as error bars representing standard errors of the means.

\section{RESULTS AND DISCUSSION}

Salt stress actually caused a significant $(P<0.05)$ reduction of cotton plants growth, but the growth of cotton plants gradually recovered after salt stress relief (Table 2). In the present study, the growth rate of root and shoot significantly $(P<0.05)$ increased after the salt content of soil grown cotton reduced from $0.5 \%$ to $0.2 \%$ level at cotton squaring stage, even approximated that of the control (the salt content of soil was maintained at $0.2 \%$ during whole cotton growth period) after a recovery period of $21 \mathrm{~d}$ from salt stress. This effect was more pronounced in 'Lumianyan 37', whose growth rate of root and shoot was increased by $71.4 \%$ and $110.0 \%$ (2011) compared with the salt-stressed cotton plants after a recovery period of $21 \mathrm{~d}$ from salt stress, while increase in growth rate of root and shoot of 'Sumian 22' was only $53.8 \%$ and $85.9 \%$ (2011). This result indicated that the capacity of recovery from salt stress in 'Lumianyan 37 ' is better than that in 'Sumian 22'.

Root vigor has been shown to be a reliable and sensitive indicator to assess adversity resistance, and reflects root metabolism activity ( $\mathrm{Li}$ et al., 2006; Wang et al., 2008; Li et al., 2011). In oil-sunflower (Chen et al., 2008) and maize (Wang et al., 2008), salt stress decreases root growth and root vigor. This was also observed in this study where root vigor of cotton plants were significantly $(P<0.05)$ 
Table 2. Growth rate of control (CK), salt-stressed (S), and saltrecovered (SR) cotton plants of two cultivars during salt stress recovery in 2011 and 2012.

\begin{tabular}{|c|c|c|c|c|c|c|c|c|}
\hline \multirow[b]{3}{*}{ Year } & \multirow[b]{3}{*}{ Cultivar } & \multirow[b]{3}{*}{ Treatment } & \multicolumn{6}{|c|}{ Growth rate $\left(\right.$ g plant $\left.^{-1} \mathrm{~d}^{-1}\right)$} \\
\hline & & & \multicolumn{3}{|c|}{ Root } & \multicolumn{3}{|c|}{ Shoot } \\
\hline & & & $\begin{array}{c}\text { Day } \\
1-7 \\
\end{array}$ & $\begin{array}{l}\text { Day } \\
8-14\end{array}$ & $\begin{array}{c}\text { Day } \\
15-21\end{array}$ & $\begin{array}{c}\text { Day } \\
1-7 \\
\end{array}$ & $\begin{array}{l}\text { Day } \\
8-14 \\
\end{array}$ & $\begin{array}{c}\text { Day } \\
15-21\end{array}$ \\
\hline \multirow[t]{6}{*}{2011} & Lumianyan 37 & $\mathrm{CK}$ & $0.24 \mathrm{a}$ & $0.25 \mathrm{a}$ & $0.26 \mathrm{a}$ & $1.06 \mathrm{a}$ & $1.27 \mathrm{a}$ & $1.31 \mathrm{a}$ \\
\hline & & $\mathrm{S}$ & $0.13 \mathrm{~b}$ & $0.12 \mathrm{c}$ & $0.14 \mathrm{~b}$ & $0.42 \mathrm{~b}$ & $0.55 \mathrm{c}$ & $0.60 \mathrm{~b}$ \\
\hline & & SR & $0.15 \mathrm{~b}$ & $0.19 \mathrm{~b}$ & $0.24 \mathrm{a}$ & $0.46 \mathrm{~b}$ & $0.82 \mathrm{~b}$ & $1.26 \mathrm{a}$ \\
\hline & Sumian 22 & CK & $0.23 \mathrm{a}$ & $0.26 \mathrm{a}$ & $0.27 \mathrm{a}$ & $1.08 \mathrm{a}$ & $1.21 \mathrm{a}$ & $1.29 \mathrm{a}$ \\
\hline & & $\mathrm{S}$ & $0.11 \mathrm{~b}$ & $0.11 \mathrm{c}$ & $0.13 \mathrm{c}$ & $0.39 \mathrm{~b}$ & $0.53 \mathrm{c}$ & $0.57 \mathrm{c}$ \\
\hline & & SR & $0.12 \mathrm{~b}$ & $0.16 \mathrm{~b}$ & $0.20 \mathrm{~b}$ & $0.43 \mathrm{~b}$ & $0.72 b$ & $1.06 \mathrm{~b}$ \\
\hline \multirow[t]{6}{*}{2012} & Lumianyan 37 & CK & $0.19 \mathrm{a}$ & $0.23 \mathrm{a}$ & $0.25 \mathrm{a}$ & $0.90 \mathrm{a}$ & $1.07 \mathrm{a}$ & $1.11 \mathrm{a}$ \\
\hline & & $\mathrm{S}$ & $0.11 \mathrm{~b}$ & $0.12 \mathrm{c}$ & $0.12 \mathrm{c}$ & $0.31 \mathrm{~b}$ & $0.39 \mathrm{c}$ & $0.43 \mathrm{c}$ \\
\hline & & SR & $0.12 b$ & $0.17 \mathrm{~b}$ & $0.21 \mathrm{~b}$ & $0.35 \mathrm{~b}$ & $0.61 \mathrm{~b}$ & $0.91 \mathrm{~b}$ \\
\hline & Sumian 22 & CK & $0.21 \mathrm{a}$ & $0.25 \mathrm{a}$ & $0.27 \mathrm{a}$ & $0.86 \mathrm{a}$ & $0.99 \mathrm{a}$ & $1.03 \mathrm{a}$ \\
\hline & & $\mathrm{S}$ & $0.11 \mathrm{~b}$ & $0.11 \mathrm{c}$ & $0.12 \mathrm{c}$ & $0.28 \mathrm{~b}$ & $0.35 \mathrm{c}$ & $0.41 \mathrm{c}$ \\
\hline & & SR & $0.12 b$ & $0.15 b$ & $0.19 b$ & $0.32 \mathrm{~b}$ & $0.56 \mathrm{~b}$ & $0.79 b$ \\
\hline
\end{tabular}

Values in the same column followed by the same letter for each cultivar are not significantly different at $P=0.05$. Values are mean of three replicates. Day 1-7: from 1 to $7 \mathrm{~d}$ after salt stress relief; Day 8-14: from 8 to $14 \mathrm{~d}$ after salt stress relief; Day 15-21: from 15 to $21 \mathrm{~d}$ after salt stress relief.

decreased by salt stress, but gradually recovered after salt stress relief and the root vigor of salt-recovered cotton plants exceeded (in 'Lumianyan 37') or approximated (in 'Sumian 22') that of the control at the $21 \mathrm{~d}$ after salt stress relief (Figure 2). Compared with the salt-stressed plants,
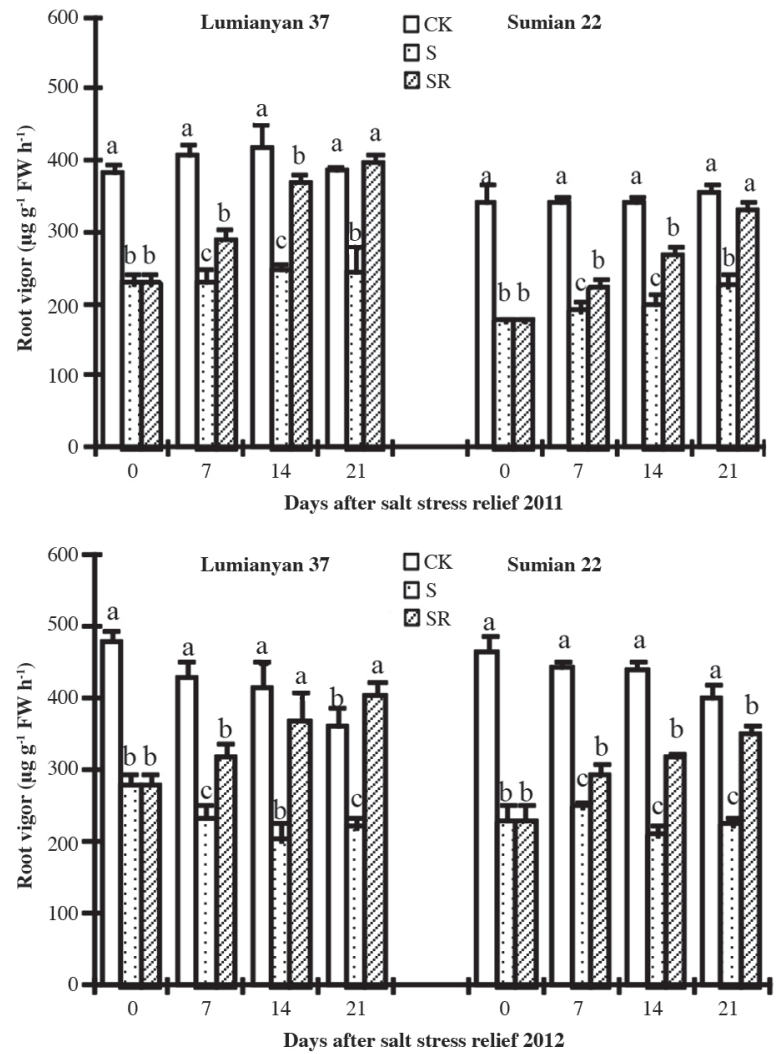

The values (means $\pm \mathrm{SE}$ ) are calculated from three replicates. Columns with the same letter are not significantly different at $\mathrm{P}=0.05$. Bars indicate SE. FW: fresh weight.

Figure 2. Root vigor of control (CK), salt-stressed (S), and saltrecovered (SR) cotton plants of two cultivars after salt stress relief in 2011 and 2012. root vigor of salt-recovered plants increased by $62.9 \%$ (2011) and $84.0 \%$ (2012) in 'Lumianyan 37', and 46.9\% (2011) and 55.5\% (2012) in 'Sumian 22' at the $21 \mathrm{~d}$ after salt stress relief, respectively. Moreover, higher level of root vigor in 'Lumianyan 37' for salt-recovered cotton plants indicated that higher root metabolism activity was beneficial to recovery of cotton growth after salt stress relief.

Salt stress has been reported to enhance the formation of reactive oxygen species (ROS) in plant, and affect plant cell membrane stability by lipid peroxidation (Munns and Tester, 2008; Oueslati et al., 2010). In our result, lipid peroxidation evaluated by MDA content in root tissue increased under salt stress. After salt stress relief, MDA content of salt-recovered cotton root gradually decreased, and was lower than that of the control in 'Lumianyan 37' at the $21 \mathrm{~d}$ after salt stress relief (Figure 3). The MDA content of salt-recovered root decreased by $28.9 \%$ (2011) and $29.4 \%$ (2012) in 'Lumianyan 37', and $13.3 \%$ (2011) and $17.2 \%$ (2012) in 'Sumian 22' compared with the saltstressed plants, respectively. A greater reduction in MDA content in root of 'Lumianyan 37' after salt stress relief, and the lower MDA content in root of 'Lumianyan 37' for salt-recovered cotton plants suggested that the root of 'Lumianyan 37' could have a better protection against oxidative damage.
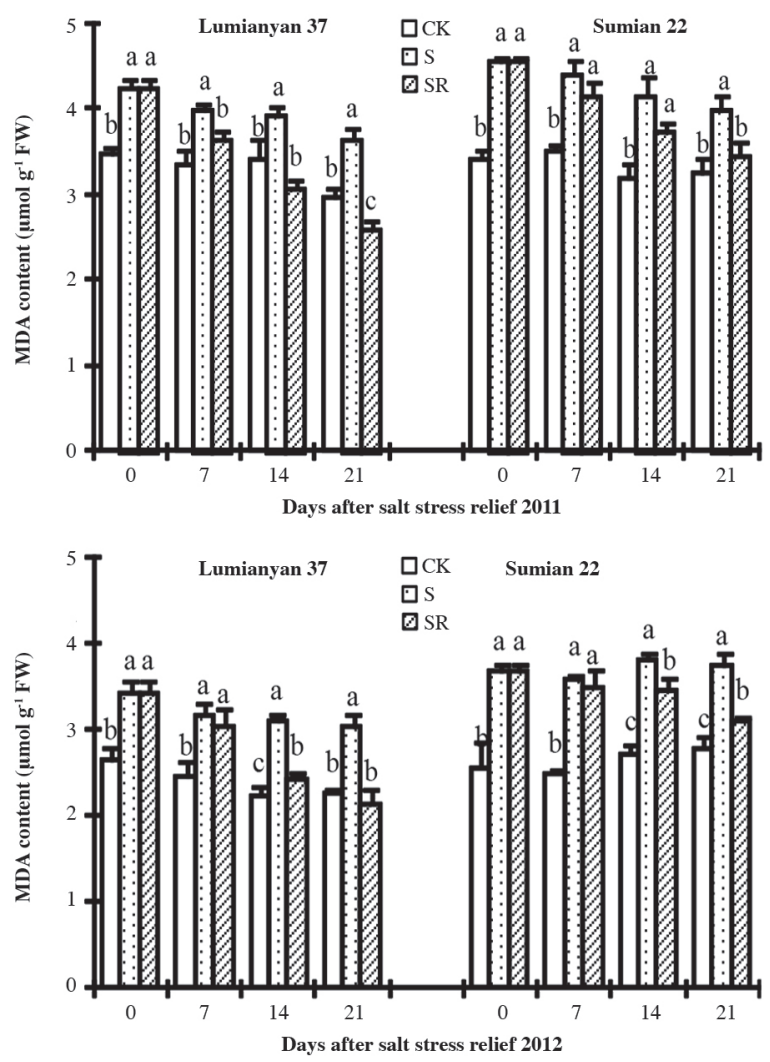

Figure 3. Malondialdehyde (MDA) content in root of control (CK), salt-stressed, (S) and salt-recovered (SR) cotton plants of two cultivars after salt stress relief in 2011 and 2012. 
As the most important components in the scavenging system of ROS, antioxidative enzymes like SOD, POD, CAT can minimize the cellular damage caused by ROS (Moradi and Ismail, 2007; Oueslati et al., 2010). Superoxide dismutase plays a key role in cellular defense mechanisms against ROS. Its activity modulates the relative amounts of $\mathrm{O}_{2}{ }^{-}$and $\mathrm{H}_{2} \mathrm{O}_{2}$, and decreases the risk of $\mathrm{OH} \bullet$ radical formation, which is highly reactive and may cause severe damage to membranes, protein and DNA (Aghaleh et al., 2011). In this work, salt stress significantly $(P<0.05)$ increased SOD activity in root of both cultivars (Figure 4), which could be a build-up of a protective mechanism to reduce oxidative damage triggered by salt stress (Sairam et al., 2005; Wang and Han, 2009). On the contrary, after salt stress relief, the SOD activity in cotton root gradually decreased compared with salt-stressed cotton plants, which seemed to imply that oxidative stress caused by salt stress gradually was relieved during salt stress recovery. However, the decreased SOD activity in root was more conspicuous in 'Sumian 22' while the SOD activity in root was higher in 'Lumianyan 37 ', suggesting that 'Lumianyan 37 ' has a better $\mathrm{O}_{2}{ }^{-}$radical scavenging ability during salt stress recovery.

The product of SOD activity is $\mathrm{H}_{2} \mathrm{O}_{2}$, which is still toxic and must be eliminated by conversion to $\mathrm{H}_{2} \mathrm{O}$ in subsequent reactions (Raza et al., 2007; Tuna et al.,
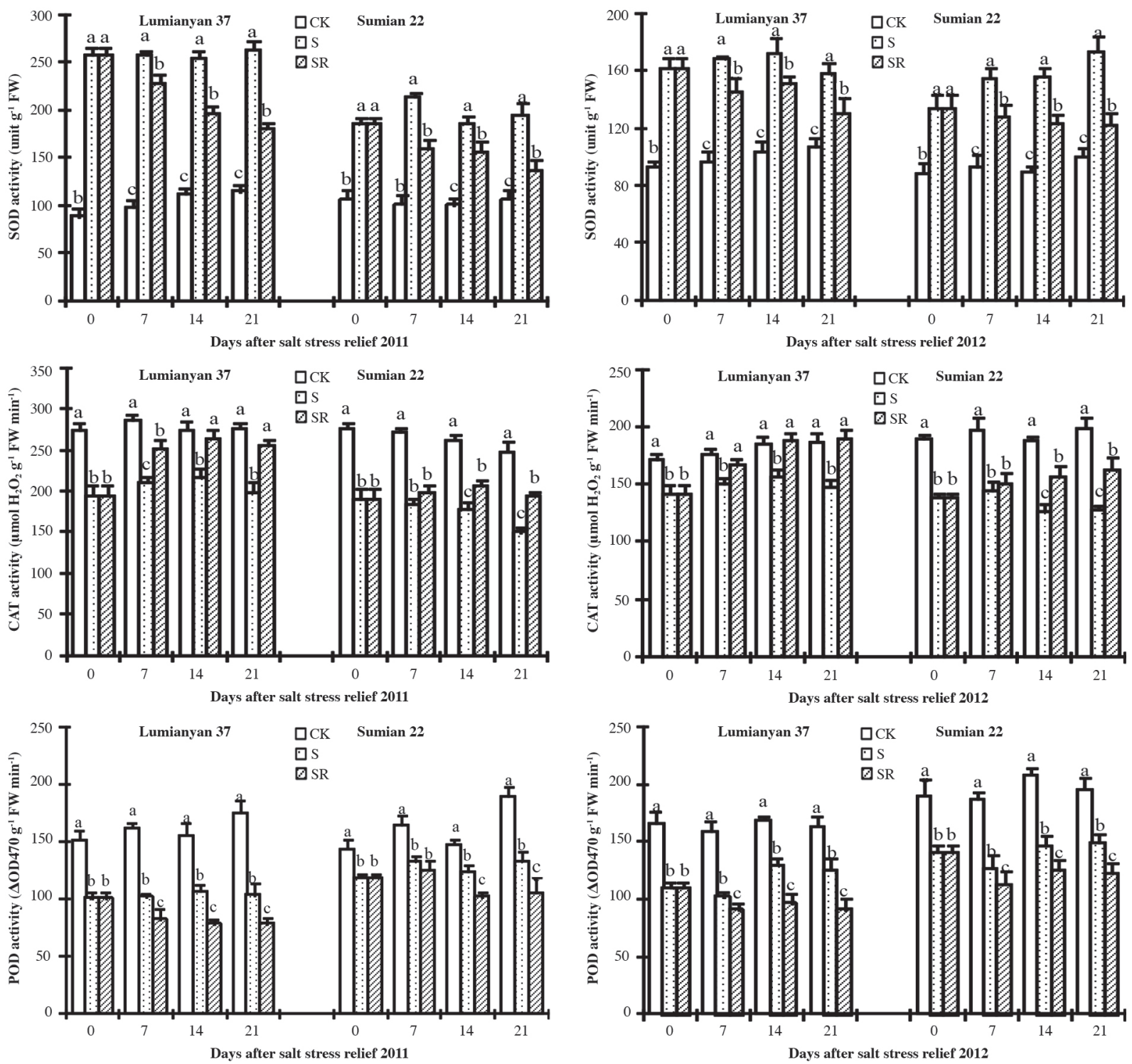

The values (mean $\pm \mathrm{SE}$ ) are calculated from three replicates. Columns with the same letter are not significantly different at $\mathrm{P}=0.05$. Bars indicate $\mathrm{SE}$. FW: fresh weight.

Figure 4. Antioxidant enzymes activity in root of control (CK), salt-stressed (S), and salt-recovered (SR) cotton plants of two cultivars after salt stress relief in 2011 and 2012. 
2008; Mallik et al., 2011). In plants, CAT and POD are considered the most important enzymes regulate $\mathrm{H}_{2} \mathrm{O}_{2}$ intracellular levels (Sairam and Tyagi, 2004). Our data showed that CAT and POD activities in root of both cultivars decreased under salt stress condition (Figure 4), which would possibly increase the accumulation of $\mathrm{H}_{2} \mathrm{O}_{2}$. After salt stress relief, the CAT activity in root significantly $(P<0.05)$ increased in both cultivars, but the POD activity was decreased compared with saltstressed cotton plants. For salt-recovered cotton root, the higher activity of CAT and the lower activity of POD coordinated with the lesser degree of membrane damage in root of 'Lumianyan 37' in comparison with 'Sumian 22' suggested that CAT activity could play a central protective role in the $\mathrm{H}_{2} \mathrm{O}_{2}$ scavenging process, and 'Lumianyan 37' had a higher capacity for the scavenging of $\mathrm{H}_{2} \mathrm{O}_{2}$ during salt stress recovery.

Salt stress condition led to the accumulation of organic solutes, such as amino acid and soluble sugar, which improve osmoprotectant, stabilizing cellular membranes and maintaining turgor pressure (Chen et al., 2011). In our results, soluble sugar and free amino acid content in cotton root significantly increased $(P<0.05)$ under salt stress condition (Figure 5), which was in agreement with study to maize (Feng et al., 2002). After salt stress relief, soluble sugar and free amino acid content in root of saltrecovered cotton plants significantly $(P<0.05)$ decreased compared with the salt-stressed plants, and lower than that of the control both two cultivars at the $21 \mathrm{~d}$ after salt stress. Such a decline in soluble sugar content and free amino acid content after salt stress relief could be due to the utilization of sugars and amino acids as energy source and nutritional components was increased (Serraj and Sinclair, 2002). Moreover, At the $21 \mathrm{~d}$ after salt stress relief, the soluble sugar content of salt-recovered root decreased by $34.2 \%$ (2011) and 33.3\% (2012) in 'Lumianyan 37', and $18.1 \%$ (2011) and $23.8 \%$ (2012) in 'Sumian 22', the free amino acid content of salt-recovered cotton root decreased by $33.3 \%$ (2011) and 39.8\% (2012) in 'Lumianyan 37', and 22.2\% (2011) and 27.8\% (2012) in 'Sumian 22', respectively. More reduction of soluble sugar and free amino acid in salt-recovered cotton root of 'Lumianyan 37 ', might contribute to better recovery of root metabolism in 'Lumianyan 37 '.

\section{CONCLUSION}

Data indicated that root and shoot growth and root vigor gradually recovered after salt stress relief even approximated that of the control after a recovery period
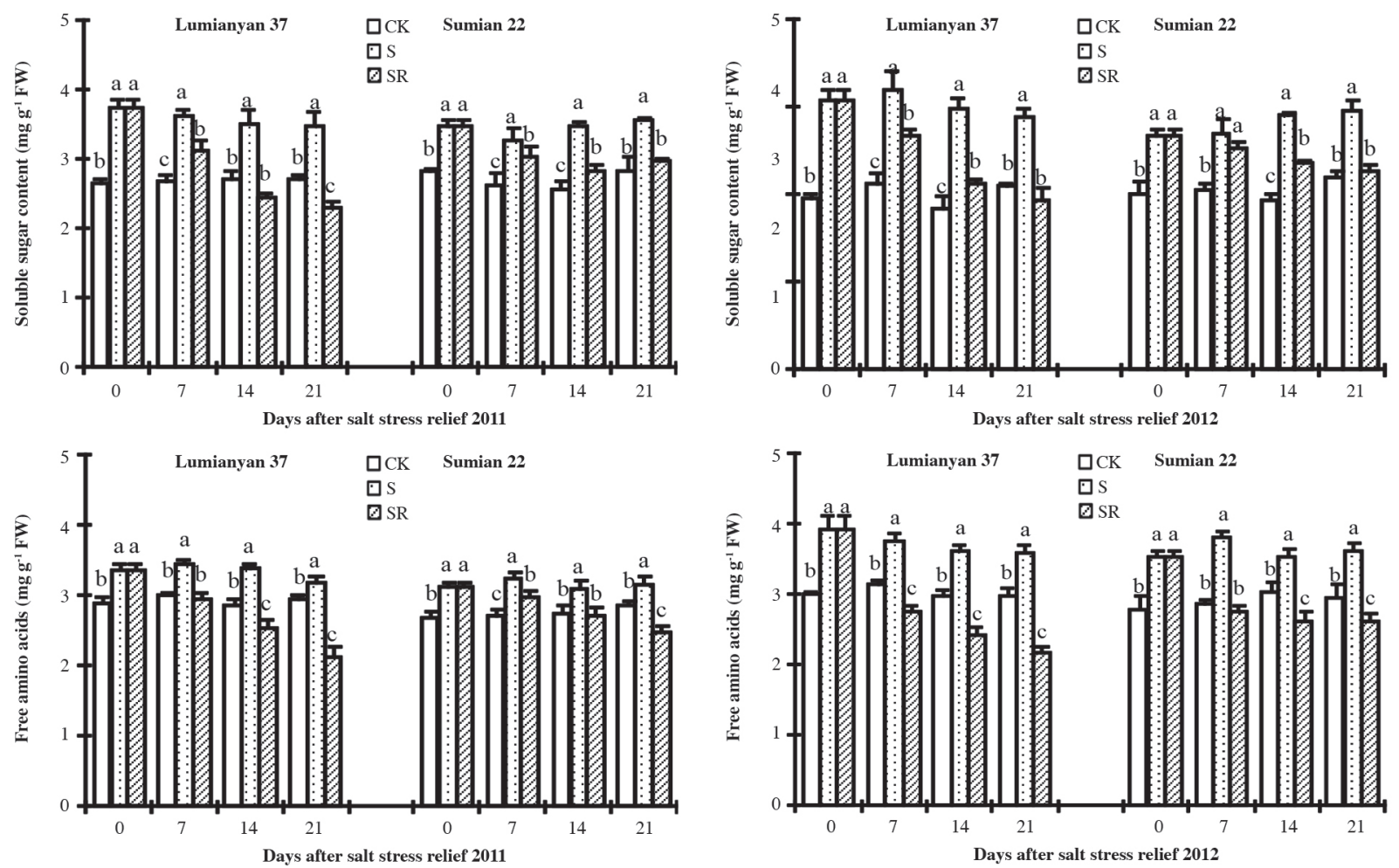

The values (mean $\pm \mathrm{SE}$ ) are calculated from three replicates. Columns with the same letter are not significantly different at $\mathrm{P}=0.05$. Bars indicate $\mathrm{SE}$. FW: fresh weight.

Figure 5. Soluble sugar and free amino acid content in root of control (CK), salt-stressed (S), and salt-recovered (SR) cotton plants of two cultivars after salt stress relief in 2011 and 2012. 
of $21 \mathrm{~d}$ from salt stress. Both the alleviation of lipid peroxidation and the reduction of organic solutes in root tissues improved the recovery of root growth and metabolism after salt stress relief. 'Lumianyan 37' could induce antioxidative system more efficiently and more reduction of organic solutes after salt stress relief, which contribute to its better recovery of root growth and metabolism, on this basis, improved better recovery of plants growth after salt stress relief.

\section{ACKNOWLEDGEMENTS}

This work was funded by the National Natural Science Foundation of China (31201139), the Jiangsu Province Natural Science Foundation (BK2011669), and Jiangsu Agricultural science and technology innovation funds (CX (11) 4010).

\section{LITERATURE CITED}

Aghaleh, M., V. Niknam, H. Ebrahimzadeh, and K. Razavi. 2011. Effect of salt stress on physiological and antioxidative responses in two species of Salicornia (S. persica and S. europaea). Acta Physiologiae Plantarum 33:1261-1270.

Ahmad, S., N. Khan, M.Z. Iqbal, A. Hussain, and M. Hassan. 2002. Salt tolerance of cotton (Gossypium hirsutum L.) Asian Journal of Plant Sciences 1:715-719.

Ashraf, M. 2002. Salt tolerance of cotton: some new advances. Critical Reviews in Plant Sciences 21:1-30.

Cavalcanti, F.R., J.P.M.S. Lima, S.L. Ferreira-Silva, R.A. Viégas, and J.A.G. Silveira. 2007. Roots and leaves display contrasting oxidative response during salt stress and recovery in cowpea. Journal of Plant Physiology 164:591-600.

Chen, W., C. Feng, W. Guo, D. Shi, and C. Yang. 2011. Comparative effects of osmotic-, salt- and alkali stress on growth, photosynthesis, and osmotic adjustment of cotton plants. Photosynthetica 49:417-425.

Chen, W.P., Z.N. Hou, L.S. Wu, Y.C. Liang, and C.Z. Wei. 2010. Effects of salinity and nitrogen on cotton growth in arid environment. Plant and Soil 326:61-73.

Chen, B.D., G.B. Huang, Y.L. Chen, H.D. Pei, Y.L. Cui, and Y. Yue. 2008. Effects of salt stress on root activity and seedling growth of oil-sunflower. Chinese Journal Oil Crop Sciences 30:327-330.

De Azevedo Neto, A.D., J.T. Prisco, J. Eneas-Filho, C.E.B. De Abreu, and E. Gomes-Filho. 2006. Effect of salt stress on antioxidative enzymes and lipid peroxidation in leaves and roots of salt-tolerant and salt-sensitive maize genotypes. Environmental and Experimental Botany 56:87-94.

de Lacerda, C.F., J. Cambraia, M.A. Oliva, and H.A. Ruiz. 2005. Changes in growth and in solute concentrations in sorghum leaves and roots during salt recovery. Environmental and Experimental Botany 54:69-76.

Dong, H.Z., X.Q. Kong, Z. Luo, W.J. Li, and C.S. Xin. 2010. Unequal salt distribution in the root zone increases growth and yield of cotton. European Journal of Agronomy 33:285-292.

Dong, H.Z., W.J. Li, W. Tang, and D.M. Zhang. 2008. Furrow seeding with plastic mulching increase stand establishment and lint yield of cotton in a saline field. Agronomy Journal 100:16401646.

Feng, G., F.S. Zhang, X.L. Li, C.Y. Tian, C. Tang, and Z. Rengel. 2002. Improved tolerance of maize plants to salt stress by arbuscular mycorrhiza is related to higher accumulation of soluble sugars in roots. Mycorrhiza 12:185-190.
Lehner, A., N. Mamadou, P. Poels, D. Côme, C. Bailly, and F. Corbineau. 2008. Changes in soluble carbohydrates, lipid peroxidation and antioxidant enzyme activities in the embryo during ageing in wheat grains. Journal of Cereal Science 47:555-565.

Li, H.S. 2000. Principles and techniques of plant physiological experiments. p. 119-120. Higher Education Press, Beijing, China.

Li, J.C., F.Z. Wei, C.R. Wang, and J. Yin. 2006. Effects of waterlogging on senescence of root system at booting stage in winter wheat. Acta Agronomica Sinica 32:1355-1360.

Li, Z.J., X.Y. Xie, S.Q. Zhang, and Y.C. Liang. 2011. Negative effects of oxytetracycline on wheat (Triticum aestivum L.) growth, root activity, photosynthesis, and chlorophyll contents. Agricultural Sciences in China 10:1545-1553.

Liu, H., Z. Xin, and Z. Zhang. 2011. Changes in activities of antioxidant-related enzymes in leaves of resistant and susceptible wheat inoculated with Rhizoctonia cerealis. Agricultural Sciences in China 10:526-533.

Mallik, S., M. Nayak, B.B. Sahu, A.K. Panigrahi, and B.P. Shaw. 2011. Response of antioxidant enzymes to high $\mathrm{NaCl}$ concentration in different salt-tolerant plants. Biologia Plantarum 55:191-195.

Meloni, D.A., M.A. Oliva, C.A. Martinez, and J. Cambraia. 2003. Photosynthesis and activity of superoxide dismutase, peroxidase and glutathione reductase in cotton under salt stress. Environmental and Experimental Botany 49:69-76.

Moradi, F., and A. Ismail. 2007. Responses of photosynthesis, chlorophyll fluorescence and ROS-scavenging systems to salt stress during seedling and reproductive stages in rice. Annals of Botany 99:1161-1173.

Munns, R. 2005. Genes and salt tolerance: bringing them together. New Phytologist 167:645-663.

Munns, R., and M. Tester. 2008. Mechanisms of salinity tolerance. Annual Review of Plant Biology 59:651-668.

Oueslati, S., N. Karray-Bouraoui, H. Attia, M. Rabhi, R. Ksouri, and M. Lachaal. 2010. Physiological and antioxidant responses of Mentha pulegium (Pennyroyal) to salt stress. Acta Physiologiae Plantarum 32:289-296.

Parida, A.K., A.B. Das, and P. Mohanty. 2004. Defense potentials to $\mathrm{NaCl}$ in a mangrove, Bruguiera parviflora: Differential changes of isoforms of some antioxidative enzymes. Journal of Plant Physiology 161:531-542.

Raza, S.H., H.R. Athar, M. Ashraf, and A. Hameed. 2007. Glycinebetaine-induced modulation of antioxidant enzymes activities and ion accumulation in two wheat cultivars differing in salt tolerance. Environmental and Experimental Botany 60:368376.

Sairam, R.K., G.C. Srivastava, S. Agarwal, and R.C. Meena. 2005. Differences in antioxidant activity in response to salinity stress in tolerant and susceptible wheat genotypes. Journal of Plant Biology 49:85-89.

Sairam, R.K., and A. Tyagi. 2004. Physiology and molecular biology of salinity stress tolerance in plants. Current Science 86:407-421.

Serraj, R., and T.R. Sinclair. 2002. Osmolyte accumulation: can it really help increase crop under drought conditions? Plant, Cell and Environment 25:333-341.

Tuna, A.L., C. Kaya, M. Dikilitas, and D. Higgs. 2008. The combined effects of gibberellic acid and salinity on some antioxidant enzyme activities, plant growth parameters and nutritional status in maize plants. Environmental and Experimental Botany 62:1-9.

Wang, X., and J. Han. 2009. Changes of proline content, activity, and active isoforms of antioxidative enzymes in two alfalfa cultivars under salt stress. Agricultural Sciences in China 8:431-440.

Wang, Y.F., Q.X. Wang, and L.W. Shang. 2008. Effects of calcium on root activity and the content of osmotic adjustable organic substances of maize seedlings under $\mathrm{NaCl}$ stress. Journal of Maize Sciences 16:66-70.

Zhang, L., B.L. Chen, G.W. Zhang, J.L. Li, Y.H. Wang, Y.L. Meng, et al. 2013. Effect of soil salinity, soil drought, and their combined action on the biochemical characteristics of cotton roots. Acta Physiologiae Plantarum 35:3167-3179. 